\title{
Plant Allelopathy in Agriculture and Its Environmental and Functional Mechanisms: A Review
}

\author{
Muhammad Mohsin Aziz ${ }^{1}$, Ali Ahmad ${ }^{1, *}$, Ehsan Ullah', Ahmad Kamal', Muhammad Yasir Nawaz ${ }^{2}$, \\ Hafiz Hussain $\mathrm{Ali}^{3}$ \\ ${ }^{1}$ Department of Agronomy, University of Agriculture Faisalabad, Faisalabad, 38000, Pakistan. \\ ${ }^{2}$ Department of Pathology, Faculty of Veterinary Science, University of Agriculture Faisalabad, Faisalabad, 38000, Pakistan. \\ ${ }^{3}$ Institute of Soil and Environmental Sciences, University of Agriculture Faisalabad, Faisalabad, 38000, Pakistan.
}

\begin{abstract}
How to cite this paper: Muhammad Mohsin Aziz, Ali Ahmad, Ehsan Ullah, Ahmad Kamal, Muhammad Yasir Nawaz, Hafiz Hussain Ali. (2021) Plant Allelopathy in Agriculture and Its Environmental and Functional Mechanisms: A Review. International Journal of Food Science and Agriculture, 5(4), 623-626.

DOI: 10.26855/ijfsa.2021.12.009
\end{abstract}

Received: September 22, 2021

Accepted: October 15, 2021

Published: October 28, 2021

*Corresponding author: Ali Ahmad, Department of Agronomy, University of Agriculture Faisalabad, Faisalabad, 38000, Pakistan.

Email: aliahmadsial2643@gmail.com

\begin{abstract}
Allelopathy is a common phenomenon by which organisms produced chemicals that influence the growth, development and reproduction of other organisms. Plant allelopathy is one of the modes of interaction between receptor and donor plants and may exert either positive effects or negative effects. The study of allelopathy increased in the 1970s and has undergone rapid development since the mid-1990s. The study of allelopathy deals with the management, ecology and agricultural production of biochemicals (allelochemicals). Allelochemicals can doubtlessly be used as increase regulators, herbicides, pesticides, and antimicrobial crop protection merchandise. Here we reviewed the plant allelopathy management practices carried out in agriculture and the underlying allelopathic mechanisms described within the literature. The main factors addressed are as follows: (1) Description of control practices related to allelopathy and allelochemicals in agriculture. (2) Dialogue of the progress concerning the mode of motion of allelochemicals and the physiological mechanisms of allelopathy, consisting of the influence on mobile micro- and ultra-shape, mobile division and elongation, membrane permeability, oxidative and antioxidant systems, boom law structures, respiratory, enzyme synthesis and metabolism, photosynthesis, mineral ion uptake, protein and nucleic acid synthesis. (3) Assessment of the impact of ecological mechanisms exerted by way of allelopathy on microorganisms and the ecological surroundings. (4) Discussion of present troubles and thought for destiny research directions in this discipline to provide a beneficial reference for destiny research on plant allelopathy.
\end{abstract}

\section{Keywords}

Allelopathy, Biochemicals, Effects, Organisms, Phenomena

\section{Introduction}

Allelopathy is a sub-discipline of chemical ecology that is concerned with the effects of chemicals produced by plants or microorganisms on the growth, development and distribution of other plants and microorganisms in natural communities or agricultural systems [1,2]. The allelopathic interaction can be one of the significant factors contributing to species distribution and abundance within plant communities and can be important in the success of invasive plants [3, 4, 5 , $6,7]$. The study of allelopathy is strategy for the management of agricultural production and ecological restoration in- 
volving the application of allelopathy and allelochemicals.

\subsection{Allelopathy and Allelochemicals}

Molish in 1937 used the definition of allelopathy first time. In 1996, the International Allelopathy Society broadened its definition of allelopathy to refer to any process involving secondary metabolites produced by plants, microorganisms, viruses and fungi that influence the growth and development of agricultural and biological systems [8]. Allelochemicals are non-nutritive substances produces as plant secondary metabolites decomposition of microorganisms are the active media of allelopathy [8].

\subsection{Arrangement of Cropping Systems}

This is the most important factor for the study of allelopathy (Figure 1). The ability of plants to suppress weeds is by crop allelopathy and competitiveness. Crop allelopathy can be effectively used to control weeds in the field and reduce inhibitory influence among allelopathic crops. To improve the utilization rate of land and to increase the annual output of the soil by establishing reasonable crop rotation and intercropping system $[9,10,11,12]$.

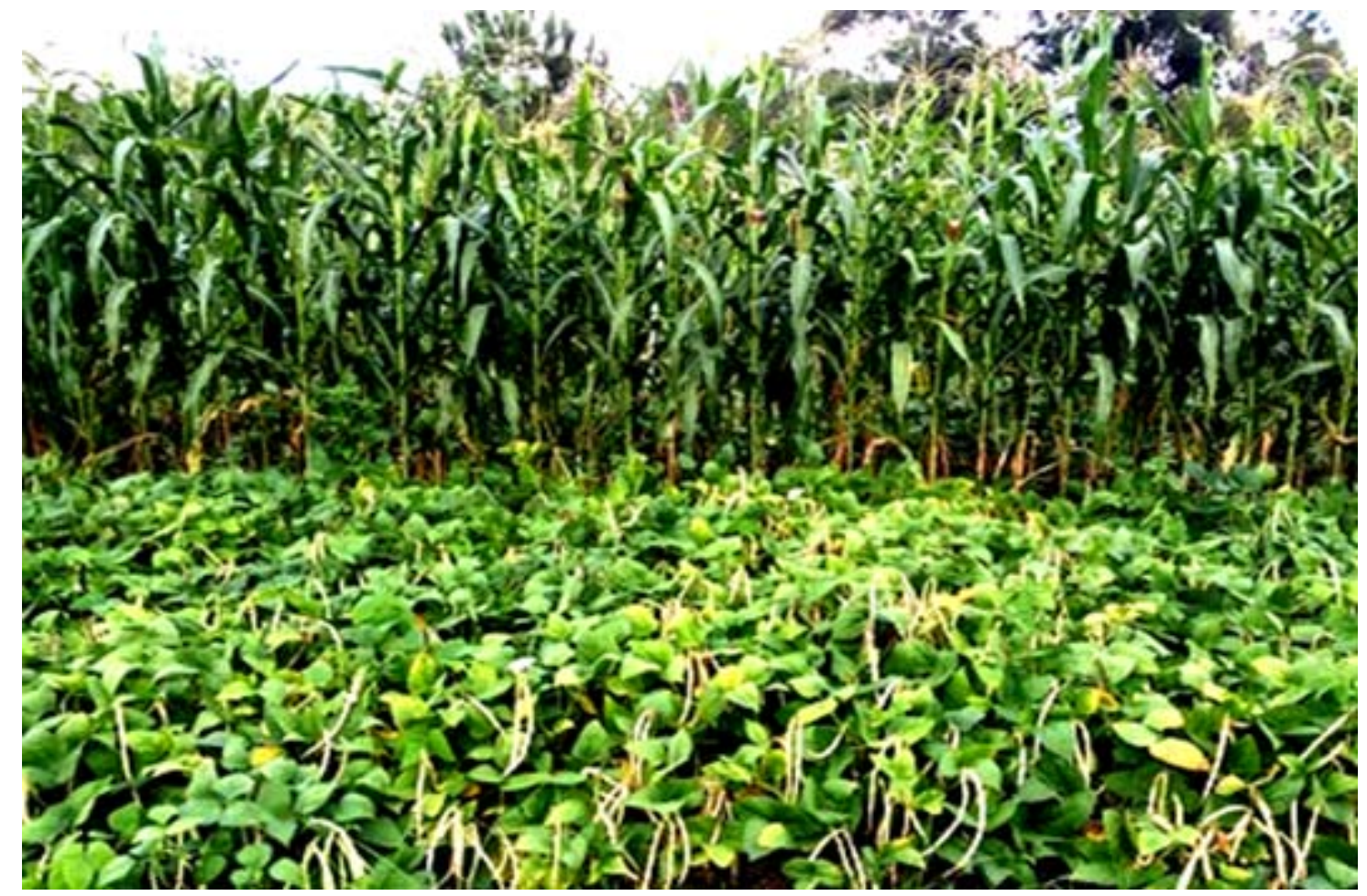

Figure 1. Intercropping of mung bean and maize, modified by Abbas et al. [9].

\subsection{Straw Mulching}

Allelopathy used for controlling of different type of weeds. Allelopathic applications, such as straw mulching, provide sustainable weed management and reducing the negative impact of agriculture on the environment [13,14]. Allelopathic plants are used as a ground cover plants provide environment friendly option [15, 16, 17].

\subsection{Breeding of Allelopathic Cultivars}

Allelopathic cultivars have great potential to minimize the efficiently control weeds in farmland ecosystems with application of allelopathy as described by Jamil et al. [18]. However, a negative effect was that the grain yield was reduced by $9 \%$ in the high allelopathic lines [19, 20].

\subsection{Effect of Plant Growth Regulator System}

Allelochemicals have plant growth regulators which inhibit the growth and development of plants, e.g., seed germination and seedling growth. IAA influences endogenous hormone levels [21]. Various phytohormones inhibit the growth, development and plant hormones which is essential for plant development. 


\subsection{Effect of Allelochemicals on Microorganisms and Ecological Environment}

Strong relationship among crop growth and soil microorganisms is under the application of allelochemicals [21, 22, 23]. Bacteria can help to increase the inhibition of different types of chemicals. Microorganisms release chemicals in ecosystems important for chemical plant to plant interaction, improve the vegetation composition and control biodiversity ecology $[24,25]$.

\section{Conclusion}

Allelopathy has been acknowledged and utilized in agriculture when you consider that historic times, however, its popularity and use in current agriculture are very confined. Allelopathy plays an important position in investigations of suitable farming systems as well as in the control of weeds, diseases and insects, the relief of continuous cropping obstacles, and allelopathic cultivar breeding. Moreover, allelochemicals can act as environmentally friendly herbicides, fungicides, pesticides and plant growth regulators, and might have remarkable cost in sustainable agriculture. Although allelochemicals (Figure 2) used as environmentally friendly herbicides has been tried for many years, there are very few natural herbicides available on the market that are derived from an allelochemical. But, there are some research investigations trying out herbal-product herbicides. With increasing emphasis on natural agriculture and environmental safety, increasing interest has been paid to allelopathy research, and the physiological and ecological mechanisms of allelopathy are regularly being elucidated. Moreover, development has been made in studies on the related molecular mechanisms. It is far obvious that allelopathy calls for in addition research for tremendous software in agricultural manufacturing worldwide.

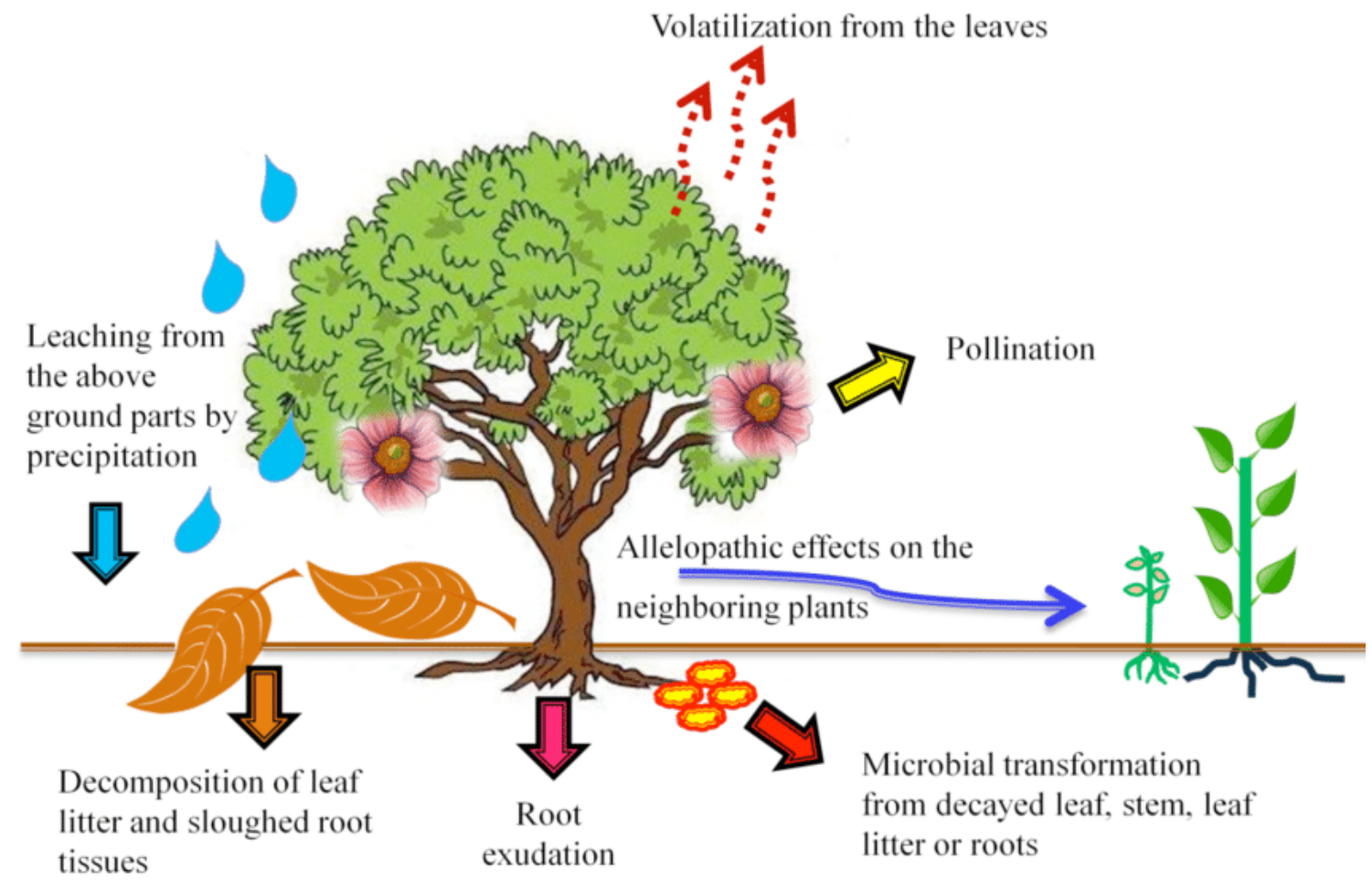

Figure 2. Possible routes of entry of allelopathic substances to the surrounding environment from the allelopathic plants modified from Chick and Kielbaso [26].

\section{References}

[1] Wang, P., Zhang, X. Y,, and Kong, C. H. (2013). The response of allelopathic rice growth and microbial feedback to barnyardgrass infestation in a paddy field experiment. Eur J Soil Biol., 56: 26-32. doi: 10.1016/j.ejsobi.2013. 01.006.

[2] Zheng, Y. L., Feng, Y. L., Zhang, L. K., Callaway, R. M., Valiente-Banuet, A., Luo, D. Q., et al. (2015). Integrating novel chemical weapons and evolutionarily increased competitive ability in success of a tropical invader. New Phytol, 205: 1350-1359. doi: 10.1111/nph.13135. 
[3] Zuo, S. P., Li, X. W., Ma, Y. Q., and Yang, S. Y. (2014). Soil microbes are linked to the allelopathic potential of different wheat genotypes. Plant Soil, 378, 49-58. doi:10.1007/s11104-013-2020-6.

[4] Cheng, F. and Cheng, Z. (2015). Research progress on the use of plant allelopathy in agriculture and the physiological and ecological mechanisms of allelopathy. Front. Plant Sci., 6: 1020. doi: 10.3389/fpls.2015.01020.

[5] Barazani, O. and Friedman, J. (1999). Allelopathic bacteria and their impact on higher plants. Crit Rev Plant Sci., 18: 741-755. doi: 10.1080/07352689991309469.

[6] Chou, C. H. (1999). Roles of allelopathy in plant biodiversity and sustainable agriculture. Crit Rev Plant Sci., 18: 609-636. doi: 10.1016/S0735-2689 (99)00393-7.

[7] Cheema, Z. A. and Khaliq, A. (2000). Use of sorghum allelopathic properties to control weeds in irrigated wheat in a semiarid region of Punjab. AgricEcosyst Environ., 79: 105-112. doi: 10.1016/S0167-8809(99)00140-1.

[8] Zhou, B., Kong, C. H., Li, Y. H., Wang, P., and Xu, X. H. (2013). Crabgrass (Digitariasanguinalis) allelochemicals that interfere with crop growth and the soil microbial community. J Agric Food Chem., 61: 5310-5317. doi: 10.1021/jf401605g.

[9] Abbas, T., Ahmad, A., Kamal, A., Nawaz, M. Y., Jamil, M. A., Saeed, T., Abid, M. A., Ali, H. A., and Ateeq, M. (2021). Ways to use allelopathic potential for weed management: a review. Int J Food SciAgric., 5(3): 492-498. doi: 10.26855/ijfsa.2021.09.020.

[10] Liebman, M. and Dyck, E. (1993). Crop-rotation and intercropping strategies for weed management. EcolAppl., 3: 92-122. doi: $10.2307 / 1941795$.

[11] Mallik, A. U. (2003). Conifer regeneration problems in boreal and temperate forests with ericaceous understory: Role of disturbance, seedbed limitation, and keystone species change. Crit Rev Plant Sci., 22: 341-366. doi: 10.1080/713610860.

[12] Narwal, S. S. (2000). Weed management in rice: wheat rotation by allelopathy. Crit Rev Plant Sci., 19: 249-266. doi: 10.1016/S0735-2689(00)80004-0.

[13] Nawaz, A., Farooq, M., Cheema, S. A., and Cheema, Z. A. (2014). "Role of allelopathy in weed management,” in Recent Advances in Weed Management, B. S. Chauhan and G. Mahajan (eds.). New York: Springer-Verlag Press, pp. 39-62.

[14] Rice, E. L. (1974). Allelopathy. New York: Academic Press.

[15] Rice, E. L. (1984). Allelopathy. 2nd ed. New York: Academic Press.

[16] Cheema, Z. A., Khaliq, A., Saeed, S. (2004). Weed control in maize (Zea mays L.) through sorghum allelopathy. J Sustain Agric., 23: 73-86. doi: 10.1300/J064v23n04_07.

[17] Cheema, Z., Farooq, M., and Khaliq, A. (2013). “Application of allelopathy in crop production: success story from Pakistan,” in Allelopathy, Cheema, Z. A., Farooq, M., and Wahid, A. (eds.). Berlin Heidelberg: Springer-Verlag Press, 113-143.

[18] Jamil, M. A., Ahmad, A., Naeem, S., Kaleem, Z., Abid, M. A., and Abbas, T. (2021). Role of allelopathy for suppression of Partheniumhysterophorus: a review. Int J Food SciAgric., 5(3): 376-380. DOI: 10.26855/ijfsa.2021.09.006.

[19] Einhellig, F. A. (1995). “Allelopathy-current status and future goals,” in Allelopathy: Organisms, Processes, and Applications, A. Inderjit, K. M. M. Dakshini, and F. A. Einhellig (eds.). Washington, DC: American Chemical Society Press, pp. 1-24.

[20] Reeves, D. W., Price, A. J., and Patterson, M. G. (2005). Evaluation of three winter cereals for weed control in conservation tillage non-transgenic cotton. Weed Technol., 19: 731-736. doi: 10.1614/WT-04-245R1.1.

[21] Singh, H. P., Batish, D. R., and Kohli, R. K. (1999). Autotoxicity: concept, organisms, and ecological significance. Crit Rev Plant Sci., 18: 757-772. doi: 10.1080/07352689991309478.

[22] Sun, X. M., Lu, Z. Y., Liu, B. Y., Zhou, Q. H., Zhang, Y. Y., and Wu, Z. B. (2014). Allelopathic effects of pyrogallic acid secreted by submerged macrophytes on Microcystis aeruginosa: role of ROS generation. Allelopathy J., 33: 121-129.

[23] Uddin, M. R., Park, K. W., Han, S. M., Pyon, J. Y., and Park, S. U. (2012). Effects of sorgoleone allelochemical on chlorophyll fluorescence and growth inhibition in weeds. Allelopathy J., 30: 61-70.

[24] Uddin, M. R., Park, S. U., Dayan, F. E., and Pyon, J. Y. (2014). Herbicidal activity of formulated sorgoleone, a natural product of sorghum root exudate. Pest ManagSci., 70: 252-257. doi: 10.1002/ps.3550.

[25] Wang, M., Wu, C., Cheng, Z., and Meng, H. (2015). Growth and physiological changes in continuously cropped eggplant (Solanummelongena L.) upon relay intercropping with garlic (Allium sativum L.). Front Plant Sci., 6: 262. doi: 10.3389/fpls.2015.00262.

[26] Chick, T. A. and Kielbaso, J. J. (1998). Allelopathy as an inhibition factor in ornamental tree growth: implications from the literature. J Arboric., 24: 274-279. 